\title{
CULTIVATION OF MYCELIUM AND THE STUDY OF THE PHYTOPATHOGENICITY OF CERTAIN XYLOTROPHIC BASIDIOMYCETES UNDER IN VITRO CONDITIONS
}

\begin{abstract}
Аннотация. В работе рассматриваются вопросы культивирования мицелия некоторых хозяйственно значимых ксилотрофных базидиомицетов с использованием методов клонального микроразмножения. Для культивирования применяются синтетические питательные среды Чапека, Мурасиге-Скуга, проводится сравнительный анализ роста мицелия на данных средах. Особое внимание уделено изучению фитопатогенных свойств мицелия, полученного in vitro. Изучаются два варианта фитопатогенности: культуральная, которая связана с характером и интенсивностью роста мицелия на питательной среде, и фитопатогенность для анатомических структур при совместном культивировании мицелия ксилотрофных базидиомицетов с частями побегов от $B$. pendula и P. tremula. Показана значительная вариативность, как по экспансивности роста мицелия, так и проявлению степени фитопатогенности у разных видов ксилотрофов. Также проведена микроскопия полученного in vitro мицелия с целью более достоверной идентификации изучаемого организма и изучения его анатомоморфологических особенностей. В целом данное исследование позволит лучше понимать экологию данных организмов в естественных условиях, проводить моделирование взаимодействия паразит-хозяин, позволит более быстро и точно проводить видовое определение фитопатогена, что можно использовать при проведении санитарно-защитных и других хозяйственных мероприятий в лесной отрасли.

Ключевые слова: ксилотрофные базидиомицеты; культивирование in vitro; среда Чапека; среда Мурасиге-Скуга (MS); Fomes fomentarius (L.) Fr.; Phellinus igniarius (L.) Quel.; Piptoporus betulinus (Bull.) P. Karst.; Inonotus obliquus (Ach. ex Pers.) Pil.; фитопатогенность.
\end{abstract}

Abstract. The paper discusses the cultivation of the mycelium of some economically significant xylotrophic basidiomycetes using methods of clonal micropropagation. For cultivation, Chapek, Murashige-Skoog synthetic synthetic media are used, a comparative analysis of mycelium growth in these media is carried out. Particular attention is paid to the study of the phytopathogenic properties of mycelium obtained in vitro. Two variants of phytopathogenicity are being studied: the cultural one, which is associated with the nature and intensity of mycelium growth on a nutrient medium, and phytopathogenicity for anatomical structures during the joint cultivation of xylotrophic basidiomycetes mycelium with parts of shoots from $B$. pendula and P. tremula. Significant variability was shown both in the expansivity of mycelial growth and in the manifestation of the degree of phytopathogenicity in different types of xylotrophs. Microscopy of the in vitro mycelium obtained was also carried out in order to more accurately identify the organism under study and to study the anatomical and morphological features. In general, this study will make it possible to better understand the ecology of these organisms in vivo, to model the interaction of the host parasite, and to more quickly and accurately conduct a specific determination of the phytopathogen, which can be used when conducting sanitary-protective and other economic activities in the forest industry.

Key words: xylotrophic basidiomycetes; in vitro cultivation; Capeca medium; Murashige-Skoog medium (MS); Fomes fomentarius (L.) Fr.; Phellinus igniarius (L.) Quel.; Piptoporus betulinus (Bull.) P. Karst.; Inonotus obliquus (Ach. Ex Pers.) Pil.; Phytopathogenicity.

Сведения об авторах: Марамохин Эдуард Владимирович, ORCID: 0000-0002-1963-5845, Костромской государственный университет, г. Кострома, Россия, maramokhin91@mail.ru; Сиротина Марина Валерьевна, ORCID: 0000-0002-7840-8861, д-р биол. наук, Костромской государственный университет, г. Кострома, Россия, mvsirotina@gmail.com; Зонтиков Дмитрий Николаевич, ORCID: 0000-0002-6668-4877, канд. с.-х. наук, Костромской государственный университет, г. Кострома, Россия, zontikovd@mail.ru.

About the authors: Maramokhin Eduard Vladimirovich, ORCID: 0000-0002-1963-5845; Kostroma State University, Kostroma, Russia, maramokhin91@mail.ru; Sirotina Marina Valerievna, ORCID: 0000-0002-7840-8861, Dr.habil., Kostroma State University, Kostroma, Russia, mvsirotina@gmail.com; Zontikov Dmitry Nikolaevich, ORCID: 0000-0002-6668-4877, Ph.D., Kostroma State University, Kostroma, Russia, zontikovd@mail.ru.

\section{Введение}

Ксилотрофные базидиомицеты играют важную роль, поскольку являются фитопатогенами хозяйственно ценных лесных культур [2;12]. Деструкция древесины, которую вызывают эти организмы, приводит к снижению ее качества, что отрицательно сказывается на объеме лесозаготовок [6]. При разрушении древесины наблюдаются изменения как ее физических, так и химических 
свойств, что в свою очередь приводит к серьезным экономическим потерям [3; 10]. Поэтому требуется серьезный подход в изучении особенностей ростовых процессов и фитопатогенности данной группы базидиомицетов, что позволяют сделать методы, применяемые при культивировании в условиях in vitro.

Развитие биотехнологии как прикладной отрасли биологии позволяет выращивать мицелий ксилотрофных базидиомицетов в чистой культуре. Для этой группы организмов отмечено достаточно легкое выделение чистой культуры из природных объектов, быстрый рост на синтетических питательных средах, они не требовательны к богатству элементарного состава питательных сред [4]. Кроме того, методы, применяемые в биотехнологии, позволят изучить фитопатогенность как экологическое явление взаимодействия ксилотрофных базидиомицетов с организмом-хозяином, а именно мелколиственными хозяйственно ценными породами деревьев.

Цель работы - изучить особенности культивирования и фитопатогенность мицелия некоторых ксилотрофных базидиомицетов на разных синтетических питательных средах.

\section{Материалы и методы исследования}

В качестве объектов исследования нами были выбраны следующие ксилотрофные базидиомицеты: Fomes fomentarius (L.) Fr., Phellinus igniarius (L.) Quel., Piptoporus betulinus (Bull.) P. Karst., Inonotus obliquus (Ach. ex Pers.) Pil. [1]. Для этой группы организмов характерны макроскопические плодовые тела, которые примыкают одной из сторон к дереву с плотной консистенцией ткани. Для изучения особенностей ростовых процессов мицелия ксилотрофов были использованы методы, которые широко используются в биотехнологии растительных объектов. Плодовые тела были отобраны в березняке и осиннике Костромского, Красносельского и Кологривского районов Костромской области.

Для изучения была отобрана центральная мицелиальная часть у молодых плодовых тел F. fomentarius, P. igniarius, P. betulinus, I. obliquus [8; 13]. Проведена дробная стерилизация отобранного материала при следующем режиме: 1) погружение в $70 \%$-ный этанол с экспозицией 1 мин; 2) выдерживание в 3\%-ном гипохлорите натрия в течение 15 мин; 3) промывание материала в стерильной дистиллированной воде; 4) экспозиция в стерильной дистиллированной воде в течение 5 мин для окончательного удаления стерилизующего агента. Затем производилась инокуляция мицелия в условиях ламинарного укрытия [7].

Культивирование мицелия ксилотрофных базидиомицетов проводили на специализированной для микобионтов питательной среде Чапека и на среде Мурасиге-Скуга (MS), которая применяется для культивирования растительных объектов (табл. 1) [11; 14].

Таблица 1

Состав питательных сред для культивирования ксилотрофных базидиомицетов

\begin{tabular}{|c|c|c|c|c|c|}
\hline \multirow{2}{*}{$\begin{array}{c}\text { Компоненты } \\
\text { среды }\end{array}$} & \multicolumn{2}{|c|}{ Концентрация веществ, мг/л } & \multirow{2}{*}{ Компоненты среды } & \multicolumn{2}{|c|}{ Концентрация веществ, мг/л } \\
\hline & MS & Чапека & & MS & Чапека \\
\hline $\mathrm{NH}_{4} \mathrm{NO}_{3}$ & 1650 & - & $\mathrm{FeSO}_{4} \cdot 7 \mathrm{H}_{2} \mathrm{O}$ & 27,8 & - \\
\hline $\mathrm{KNO}_{3}$ & 1900 & - & $\mathrm{Na}_{2}$ ЭДТА· $2 \mathrm{H}_{2} \mathrm{O}$ & 37,2 & - \\
\hline $\mathrm{KH}_{2} \mathrm{PO}_{4}$ & 170 & 1000 & Инозитол & 100 & - \\
\hline $\mathrm{CaCl}_{2} \cdot 2 \mathrm{H}_{2} \mathrm{O}$ & 340 & - & Кальция пантотенат & 0,5 & - \\
\hline $\mathrm{MnSO}_{4} \cdot 4 \mathrm{H}_{2} \mathrm{O}$ & 22,3 & - & Никотиновая кислота & 0,5 & - \\
\hline $\mathrm{MgSO}_{4} \cdot \mathrm{H}_{2} \mathrm{O}$ & 370 & 500 & Тиамин & 0,5 & 1 \\
\hline $\mathrm{H}_{3} \mathrm{BO}_{3}$ & 6,2 & - & Пиридоксин & 0,5 & - \\
\hline $\mathrm{ZnSO}_{4} \cdot 7 \mathrm{H}_{2} \mathrm{O}$ & 8,6 & 0,5 & Глицин & 2 & - \\
\hline $\mathrm{KI}$ & 0,83 & - & Caxapoza & 25000 & 6000 \\
\hline $\mathrm{CuSO}_{4} \cdot 5 \mathrm{H}_{2} \mathrm{O}$ & 0,025 & - & Мальтоза & - & 4000 \\
\hline $\mathrm{Na}_{2} \mathrm{MoO}_{4} \cdot 2 \mathrm{H}_{2} \mathrm{O}$ & 0,25 & & Агар «Биолот» & 5000 & 6000 \\
\hline $\mathrm{CoCl}_{2} \cdot 6 \mathrm{H}_{2} \mathrm{O}$ & 0,025 & & $\mathrm{pH}$ & 5,7 & 5,7 \\
\hline
\end{tabular}

Также использовались питательные среды MS и Чапека с частями стерильной древесины Betula pendula Roth. и Populus tremula L. для оценки фитопатогенности мицелия [5]. Древесину стерилизовали в сухожаровом шкафу при $160^{\circ} \mathrm{C} 2,5$ ч. Культивирование осуществляли на световых стеллажах при интенсивности освещенности 2500 люкс и температуре $25^{\circ} \mathrm{C}$ [9]. 
Результаты культивирования проверялись на 15-20-е сутки. При этом была проведена оценка морфологии и микроскопической структуры мицелия. Стерильный мицелий ксилотрофов был изучен с использованием световой микроскопии (микроскоп «Биомед-3»), увеличение - х600 [15].

\section{Результаты и их обсуждение}

Наиболее активный рост мицелия наблюдался на питательной среде MS: мицелий от белого до почти черного цвета распространялся как по поверхности питательной среды (P. betulinus), так и проникал вглубь (I. obliquus, F. fomentarius, P. igniarius). Стоит отметить, что рост мицелия P. betulinus на питательной среде начался более интенсивно и в более ранние сроки, чем у других изучаемых ксилотрофов, это можно объяснить более мягкой структурой плодового тела березовой губки. При дальнейшем изучении мицелия отмечался сильный грибной запах, характерный для ксилотрофных базидиомицетов. При этом не было замечено спороношения мицелия (табл. 2). Эти признаки говорят о том, что на питательной среде отмечался именно рост мицелия ксилотрофов, что позволяет исключить контаминацию и идентифицировать культивируемые объекты. Питательная среда Чапека по многим показателям уступала среде MS. B первую очередь отмечался более медленный рост мицелия, а прирост по биомассе на 30-й день культивирования при средних значениях для всех культур также оказался менее продуктивным именно на данной питательной среде (рис. 1). Это, конечно, связано с достаточно бедным содержанием в среде Чапека макро- и микроэлементов, а также некоторых органических веществ, необходимых для развития живых организмов и, в частности, мицелия ксилотрофов. Но это также является и преимуществом при выращивании мицелия в промышленных масштабах (например, для нужд фармацевтической промышленности), так как значительно удешевляет получаемую биомассу вследствие малого расхода компонентов для питательной среды [16].

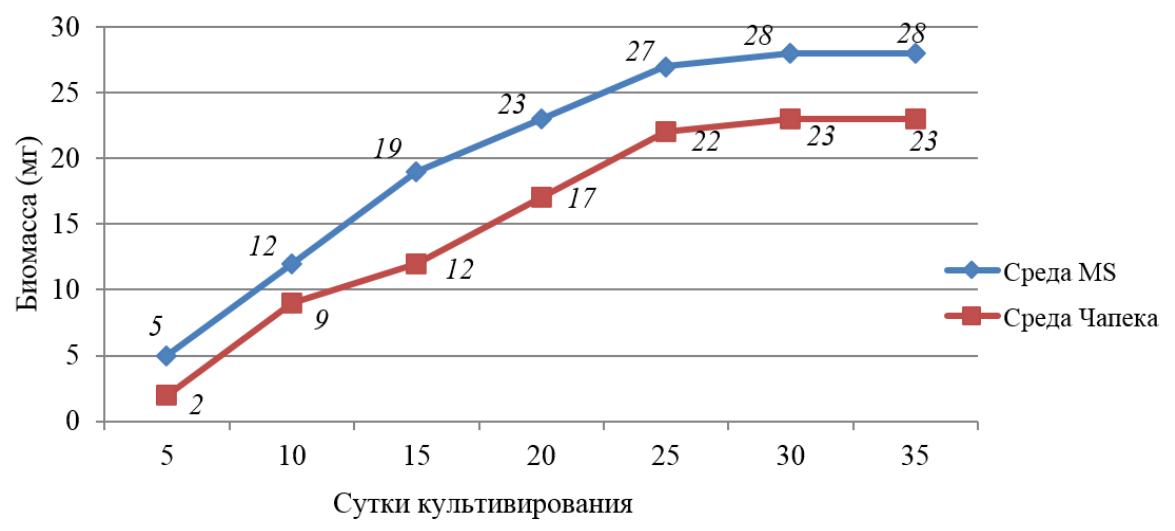

Рис. 1. Влияние типа питательной среды на прирост биомассы мицелия (среднее значение для всех культур)

Проводилась серия опытов по совместному культивированию выделенного мицелия с частями древесины деревьев, к которым данные ксилотрофы проявляли тропность. В дальнейшем с использованием микроскопии изучали морфологию мицелия и проводили оценку его прорастания в древесину. Такое исследование необходимо для определения степени фитопатогенности объекта. Оценку результатов производили через 35-40 суток. Результаты роста, морфологии и микроскопии мицелия были сведены в таблицу (табл. 2).

Таблица 2

Сравнительная анатомо-морфологическая характеристика мицелия разных видов ксилотрофных базидиомицетов

\begin{tabular}{|c|c|}
\hline Оцениваемый признак & Анатомо-морфологическая характеристика мицелия \\
\hline \multicolumn{2}{|r|}{ Piptoporus betulinus (Bull.) P.Karst., 1881} \\
\hline $\begin{array}{l}\text { Особенности роста на пита- } \\
\text { тельных средах }\end{array}$ & $\begin{array}{l}\text { Мицелий белого цвета распространялся исключительно по поверхности пи- } \\
\text { тательной среды, отмечался сильный грибной запах, характерный для данно- } \\
\text { го вида. Спороношения нет }\end{array}$ \\
\hline $\begin{array}{l}\text { Культуральная } \text { фитопато- } \\
\text { генность }\end{array}$ & $\begin{array}{l}\text { Выраженная ксилотропность по отношению к } B \text {. pendula. Быстрый экспан- } \\
\text { сивный рост нитей мицелия и ориентация их к древесине }\end{array}$ \\
\hline Морфология мицелия & $\begin{array}{l}\text { Мицелий по морфологии слабоветвящийся, септированный, имеет единич- } \\
\text { ные молодые зачатки гиф. Спороношения нет }\end{array}$ \\
\hline
\end{tabular}




\begin{tabular}{|c|c|}
\hline \multirow{2}{*}{\multicolumn{2}{|c|}{$\begin{aligned} \text { Окончание таблицы } 2 \\
\text { Анатомо-морфологическая характеристика мицелия }\end{aligned}$}} \\
\hline & \\
\hline $\begin{array}{l}\text { Фитопатогенность для ана- } \\
\text { томических структур }\end{array}$ & $\begin{array}{l}\text { Был выявлен рост мицелия в пробковую и коровую части стебля березы с } \\
\text { незначительным проникновением в ксилему. Умеренно выраженная фитопа- } \\
\text { тогенность }\end{array}$ \\
\hline \multicolumn{2}{|r|}{ Inonotus obliquus (Ach. ex Pers.) Pilát (1942) } \\
\hline $\begin{array}{l}\text { Особенности роста на пита- } \\
\text { тельных средах }\end{array}$ & $\begin{array}{l}\text { Мицелий темно-коричневого цвета, проникает вглубь питательной среды, } \\
\text { характерен медленный рост. Спороношения нет }\end{array}$ \\
\hline $\begin{array}{l}\text { Культуральная фитопато- } \\
\text { генность }\end{array}$ & $\begin{array}{l}\text { Фитопатогенность выражена слабо, мицелий прорастает в среду медленно, } \\
\text { ксилотропность по отношению к } B \text {. pendula не выявлена }\end{array}$ \\
\hline Морфология мицелия & Тонкие, умеренно септированные гифы \\
\hline $\begin{array}{l}\text { Фитопатогенность для ана- } \\
\text { томических структур }\end{array}$ & $\begin{array}{l}\text { Малопатогенный ксилотроф, за коровую часть стебля гифы гриба не прони- } \\
\text { кают, разрушение древесины не отмечено }\end{array}$ \\
\hline \multicolumn{2}{|r|}{ Fomes fomentarius (L.) Fr., 1849} \\
\hline $\begin{array}{l}\text { Особенности роста на пита- } \\
\text { тельных средах }\end{array}$ & $\begin{array}{l}\text { Мицелий полиморфен от белого до почти черного цвета, гифы располагают- } \\
\text { ся плотно и фрагментарно на поверхности питательной среды. Спороноше- } \\
\text { ния нет }\end{array}$ \\
\hline $\begin{array}{l}\text { Культуральная фитопато- } \\
\text { генность }\end{array}$ & $\begin{array}{l}\text { Ксилотропный рост мицелия выражен умеренно, тенденция к общей экспан- } \\
\text { сии гиф гриба по поверхности питательной среды со слабым проникновени- } \\
\text { ем вглубь }\end{array}$ \\
\hline Морфология мицелия & $\begin{array}{l}\text { Мицелий слабо септирован, гифы хорошо выражены, плотно переплетены } \\
\text { между собой, создавая при этом плотные структуры на поверхности среды }\end{array}$ \\
\hline $\begin{array}{l}\text { Фитопатогенность для ана- } \\
\text { томических структур }\end{array}$ & Мицелий прорастает в коровый слой и частично внедряется в ксилему \\
\hline \multicolumn{2}{|r|}{ Phellinus igniarius (L.) Quél. (1886) } \\
\hline $\begin{array}{l}\text { Особенности роста на пита- } \\
\text { тельных средах }\end{array}$ & $\begin{array}{l}\text { Мицелий бесцветен, характерна тонкая мицелиальная структура, которая } \\
\text { активно внедряется в субстрат. Спороношения нет }\end{array}$ \\
\hline $\begin{array}{l}\text { Культуральная фитопато- } \\
\text { генность }\end{array}$ & $\begin{array}{l}\text { Очень высокая, мицелий локализован преимущественно на части древесины, } \\
\text { отмечено образование примордия }\end{array}$ \\
\hline Морфология мицелия & $\begin{array}{l}\text { Сложная структура, мицелий слабо септирован, гифы окрашены в коричне- } \\
\text { вый цвет, образуют петли и структуры с неустановленным функциональным } \\
\text { значением }\end{array}$ \\
\hline $\begin{array}{l}\text { Фитопатогенность для ана- } \\
\text { томических структур }\end{array}$ & $\begin{array}{l}\text { Отмечена крайняя степень патогенности, мицелий полностью разрушает все } \\
\text { слои древесины до состояния трухи }\end{array}$ \\
\hline
\end{tabular}

Особое внимание следует уделить морфологии мицелия и фитопатогенности для анатомических структур, поскольку именно эти параметры во многом определяют взаимодействие ксилотрофных базидиомицетов с организмом-хозяином. Так, например, у I. obliquus отмечается тонкий септированный мицелий и слабое фитопатогенное влияние на структуру древесины при совместном культивировании, поэтому в природных условиях данный ксилотроф практически никогда не встречается на мертвых деревьях (рис. 2).
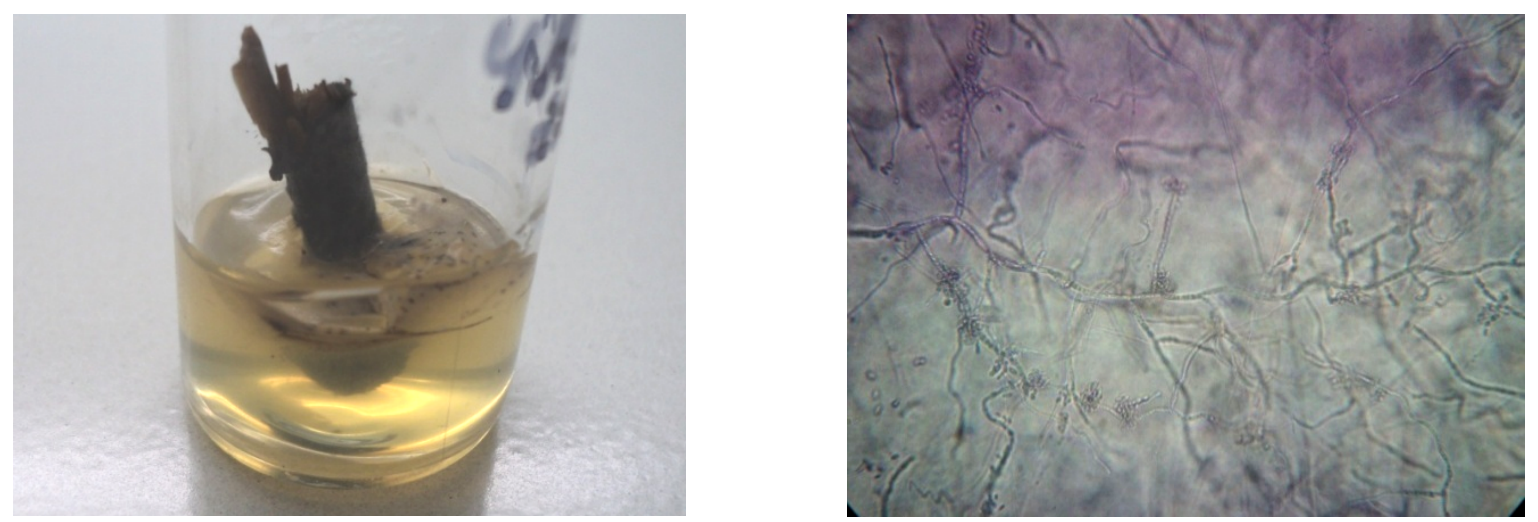

Рис. 2. Культивирование I. obliquus на питательной среде MS (слева), морфология мицелия I. obliquus при микроскопировании с увеличением ×600 (справа) 
Морфология мицелия P. igniarius отличается мощностью гиф, сложной слабо септированной структурой с петлями и неустановленными элементами, при этом данный ксилотроф отличается исключительной агрессивностью по отношению к древесине Populus tremula L. и при совместном культивировании вызывает не только полное ее разрушение, но и образование примордия (рис. 3).

В природе P. igniarius также проявляет высоко патогенные свойства и при заражении дерева приводит к развитию сердцевинной гнили и быстрой гибели дерева. Отмечается также значительное образование плодовых тел. Стоит отметить, что только при культивировании данного ксилотрофного базидиомицета в условиях in vitro удалось получить примордий, что говорит и об агрессивном характере распространения данного фитопатогена.
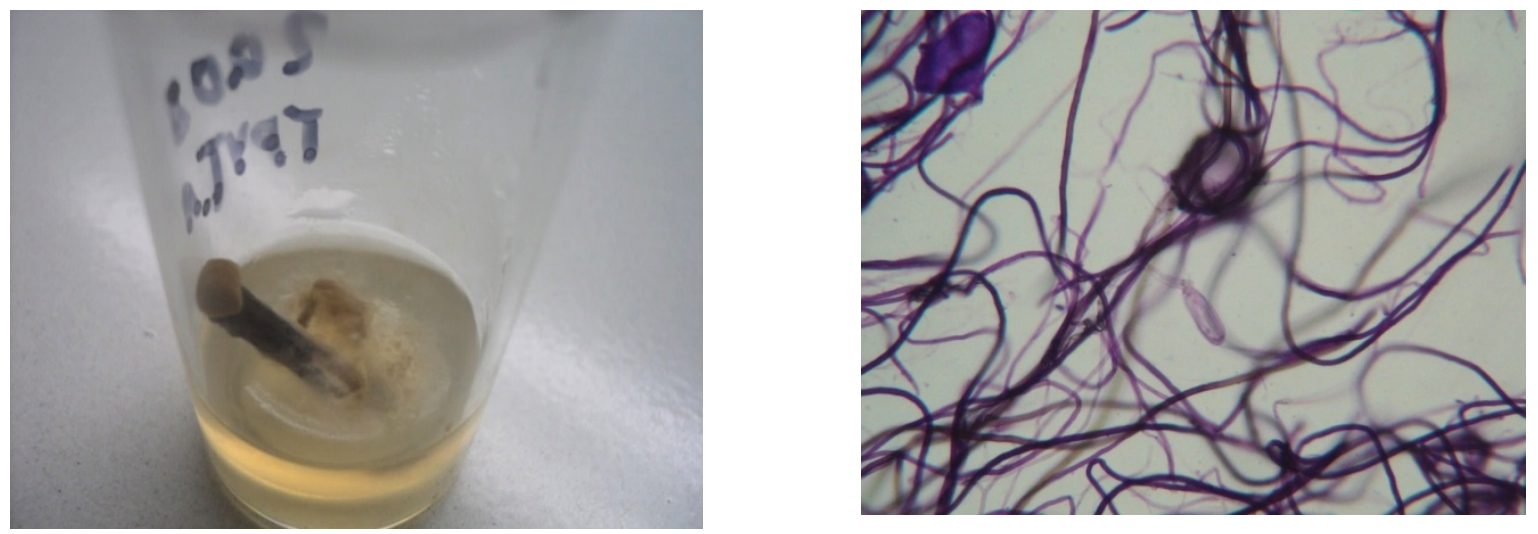

Рис. 3. Культивирование P. igniarius на питательной среде MS и образование примордия на части древесины P. tremula (слева), морфология мицелия P. igniarius при микроскопировании с увеличением ×600 (справа)

Что касается таких ксилотрофных базидиомицетов как P. betulinus и $F$. fomentarius, стоит отметить их умеренную фитопатогенность по отношению к организму-хозяину, в природе эти виды предпочитают селиться на уже погибшие или сильно ослабленные мелколиственные породы и преимущественно на Betula pendula Roth. Что, однако, не говорит о том, что они не способны нанести ущерб лесному хозяйству.

\section{Заключение}

Используя методы, применяемые при клональном микроразмножении растений, удалось получить чистые культуры in vitro ксилотрофных базидиомицетов Fomes fomentarius (L.) Fr., Phellinus igniarius (L.) Quél, Piptoporus betulinus (Bull.) P.Karst., Inonotus obliquus (Ach. ex Pers.) Pilát. Проведено детальное изучение морфологии, анатомии и микроскопического строения мицелия этих объектов, также особое внимание было уделено изучению степени фитопатогенности и ее проявлений для анатомических структур организма-хозяина. Наиболее агрессивным ксилотрофным базидиомицетом оказался P. igniarius, который преимущественно поражает Populus tremula L. Фитопатогены Betula pendula Roth. оказались умеренно или слабопатогенными как по ксилотропности, так и по характеру проникновения в коровую часть и разрушению древесины. Полученные данные позволят лучше понимать особенности взаимодействия паразитических базидиомицетов с организмом-хозяином, а также проливают свет на экологию ксилотрофных базидиомицетов, что в свою очередь можно использовать при проведении лесотехнических и санитарных мероприятий по борьбе с фитопатогенами и для повышения качества древесины, получаемой от мелколиственных пород.

\section{ЛИТЕРАТУРА} 391 c.

1. Бондарцева М. А. Определитель грибов России (порядок Афиллофоровые). Л.: Наука, 1998. Вып. 2.

2. Бондарцева М. А. Эколого-биологические закономерности функционирования ксилотрофных базидиомицетов в лесных экосистемах // Грибные сообщества лесных экосистем. Петрозаводск: Карельский НЦ PAH, 2000. С. 9-25.

3. Змитрович И. В., Фирсов Г. А., Бондарцева М. А., Волобуев С. В., Большаков С. Ю. Базидиомицеты - возбудители хронических гнилей деревьев ботанического сада Петра Великого ботанического института имени В. Л. Комарова РАН: диагностика, биология, распределение по территории // Hortus Botanicus. 2018. № 13(13). C. 182-204. http://hb.karelia.ru/journal/atricle.php?id=5082 
4. Ильина Г. В. Ксилотрофные базидиомицеты в чистой культуре. Пенза: ПГАУ, 2013. 222 с.

5. Ильин Д. Ю., Ильина Г. В., Сашенкова С. А., Шкаев Н. В., Филатов А. Экологические аспекты лабораторного культивирования природных изолятов ксилотрофных базидиомицетов, распространенных в Пензенской области и перспективных в биотехнологии // Нива Поволжья. 2015. № 4(37). С. 44-53.

6. Камзолкина О. В., Биланенко Е. Н., Штаер О. В., Дольникова Г. А., Мухин В. А.Топология мицелия Fomes fomentarius, Fomitopsis pinicola, Piptoporus betulinus и сопутствующих им грибов и бактерий в древесном субстрате березы // Микология и фитопатология. 2012. Т. 46. № 3. С. 210-216.

7. Марамохин Э. В., Малахова К. В. Изучение лесных фитопатогенов группы ксилотрофных базидиомицетов на примере Piptoporus betulinus (Bull.) P. Karst. и Phellinus igniarius (L.) Quel. в культуре in vitro // Инженерные кадры - будущее инновационной экономики России. 2018. № 2. С. 74-77.

8. Марамохин Э. В. Особенности культивирования ксилотрофного базидиомицета Piptoporus betulinus (Bull.) P. Karst. на синтетических питательных средах в условиях in vitro // Инновационные подходы к развитию науки и производства регионов: Сб. науч. тр. научно-практической конференции (12-14 февраля 2019 г.). Тверь, 2019. С. 97-99.

9. Марамохин Э. В., Малахова К. В., Зонтиков Д. Н., Сиротина М. В. Перспективы получения биологически активных веществ из культуры ткани некоторых ксилотрофных базидиомицетов // Роль метаболомики в совершенствовании биотехнологических средств производства: Сб. тр. II международной научной конференции (6-7 июня 2019 г.). М., ВИЛАР, 2019. С. 159-162.

10. Сафонов М. А., Устинова Г. М. Субстратная специализация ксилотрофных грибов, как фактор, определяющий их расселение // Вертикаль: вестник молодой науки Урала. 1997. Т. 2. № 1. С. 128-130.

11. Сашенкова С. А., Ильина Г. В., Ильин Д. Ю. Изучение влияния обогащения питательных сред и субстратов микроэлементами германием и селеном при культивировании базидиальных грибов // Экологические проблемы и здоровье населения: материалы II Всероссийской научно-практической конференции. Пенза: ПГАУ, 2017. С. 48-51.

12. Burdon J. J., Thrall P. H. Spatial and temporal patterns in coevolving plant and pathogen associations // The American Naturalist. 1999. V. 153. № S5. P. S15-S33. https://doi.org/10.1086/303209

13. Krupodorova T. A., Barshteyn V. Y. Alternative substrates for higher mushrooms mycelia cultivation // Journal of BioScience \& Biotechnology. 2015. V. 4. № 3. P. 339-347.

14. Lemieszek M. K., Langner E., Kaczor J., Kandefer-Szerszen M., Sanecka B., Mazurkiewicz W., Rzeski W. Anticancer effect of fraction isolated from medicinal Birch polypore mushroom, Piptoporus betulinus (Bull.: Fr.) P. Karst. (Aphyllophoromycetideae): In vitro studies // International Journal of Medicinal Mushrooms. 2009. V. 11. № 4. P. 351-364. https://doi.org/10.1615/IntJMedMushr.v11.i4.20

15. Leviu L., Castro M. A. Anatomical study of the decay caused by the white-rot fungus Trametes trogii (Aphyllophorales) in wood of Salix and Populus // IAWA journal. 1998. V. 19. № 2. P. 169-180. https://doi.org/10.1163/22941932-90001519

16. Pleszczyńska M., Wiater A., Siwulski M., Lemieszek M. K., Kunaszewska J., Kaczor, J., Szczodrak J. Cultivation and utility of Piptoporus betulinus fruiting bodies as a source of anticancer agents // World Journal of Microbiology and Biotechnology. 2016. V. 32. № 9. P. 151. https://doi.org/10.1007/s11274-016-2114-4

\section{REFERENCES} Russian).

1. Bondartseva, M. A. (1998). Opredelitel' gribov Rossii (poryadok Afilloforovye). Leningrad, Nauka. (In

2. Bondartseva, M. A. (2000). Ekologo-biologicheskie zakonomernosti funktsionirovaniya ksilotrofnykh bazidiomitsetov v lesnykh ekosistemakh. In Gribnye soobshchestva lesnykh ekosistem. Petrozavodsk, 9-25. (In Russian).

3. Zmitrovich, I. V., Firsov, G. A., Bondartseva, M. A., Volobuev, S. V., \& Bolshakov, S. Yu. (2018). Woodinhabiting basidiomycetes as tree pathogens at the Peter the Great Botanical Garden of Komarov Botanical Institute of the Russian Academy of Science: their diagnostics, biology, and distribution over. Hortus Botanicus, 13(13). 182-204. (In Russian) http://hb.karelia.ru/journal/atricle.php?id=5082

4. Ilyina, G. V. (2013). Xylotrophic basidiomycetes in pure culture. Penza. (In Russian).

5. Ilyin, D. Yu., Ilyina, G. V., Sashenkova, S. A., Shkaev, N. V., \& Filatov, A. (2015). Environmental Aspects of Laboratory Cultivation of Natural Isolates of Xylotrophic Basidiomycetes widespread in Penza region which are Promising in Biotechnology. Niva Povolzhya, 4(37). 44-53. (In Russian).

6. Kamzolkina, O. V., Bilanenko, E. N., Staer, O. V., Dolnikova, G. A., \& Mukhin, V. A. (2012). Topology of fomes fomentarius, fomitopsis pinicola and piptoporus betulinus mycelium and attendant fungi and bacteria in birch wood. Mycology and phytopathology, 46(3). 210-216. (In Russian).

7. Maramokhin, E. V., \& Malakhova, K. V. (2018). Izuchenie lesnykh fitopatogenov gruppy ksilotrofnykh bazidiomitsetov na primere Piptoporus betulinus (Bull.) P. Karst. i Phellinus igniarius (L.) Quel. v kul'ture in vitro. Inzhenernye kadry - budushchee innovatsionnoi ekonomiki Rossii, (2). 74-77. (In Russian). 
8. Maramokhin, E. V. (2019). Osobennosti kul'tivirovaniya ksilotrofnogo bazidiomitseta Piptoporus betulinus (Bull.) P. Karst. na sinteticheskikh pitatel'nykh sredakh v usloviyakh in vitro. In Innovatsionnye podkhody $k$ razvitiyu nauki i proizvodstva regionov: Sb. nauch. tr. nauchno-prakticheskoi konferentsii (12-14 fevralya 2019 g.). Tver', 97-99. (In Russian).

9. Maramokhin, E. V., Malakhova, K. V., Zontikov, D. N., \& Sirotina, M. V. (2019). Perspektivy polucheniya biologicheski aktivnykh veshchestv iz kul'tury tkani nekotorykh ksilotrofnykh bazidiomitsetov. In Rol' metabolomiki v sovershenstvovanii biotekhnologicheskikh sredstv proizvodstva: Sb. tr. II mezhdunarodnoi nauchnoi konferentsii (6-7 iyunya 2019 g.). Moscow, 159-162. (In Russian).

10. Safonov, M. A., \& Ustinova, G. M. (1997). Substratnaya spetsializatsiya ksilotrofnykh gribov, kak faktor, opredelyayushchii ikh rasselenie. Vertikal': vestnik molodoi nauki Urala, 2(1), 128-130. (In Russian).

11. Sashenkova, S. A., Il'ina, G. V., \& Il'in, D. Yu. (2017). Izuchenie vliyaniya obogashcheniya pitatel'nykh sred i substratov mikroelementami germaniem i selenom pri kul'tivirovanii bazidial'nykh gribov. In Ekologicheskie problemy i zdorov'e naseleniya: materialy II Vserossiiskoi nauchno-prakticheskoi konferentsii. Penza, 48-51. (In Russian).

12. Burdon, J. J., \& Thrall, P. H. (1999). Spatial and temporal patterns in coevolving plant and pathogen associations. The American Naturalist, 153(S5), S15-S33. https://doi.org/10.1086/303209

13. Krupodorova, T. A., \& Barshteyn, V. Y. (2015). Alternative substrates for higher mushrooms mycelia cultivation. Journal of BioScience \& Biotechnology, 4(3). 339-347.

14. Lemieszek, M. K., Langner, E., Kaczor, J., Kandefer-Szerszen, M., Sanecka, B., Mazurkiewicz, W., \& Rzeski, W. (2009). Anticancer effect of fraction isolated from medicinal Birch polypore mushroom, Piptoporus betulinus (Bull.: Fr.) P. Karst.(Aphyllophoromycetideae): In vitro studies. International Journal of Medicinal Mushrooms, 11(4). 351-364. https://doi.org/10.1615/IntJMedMushr.v11.i4.20

15. Leviu, L., \& Castro, M. A. (1998). Anatomical study of the decay caused by the white-rot fungus Trametes trogii (Aphyllophorales) in wood of Salix and Populus. IAWA journal, 19(2), 169-180. https://doi.org/10.1163/22941932-90001519

16. Pleszczyńska, M., Wiater, A., Siwulski, M., Lemieszek, M. K., Kunaszewska, J., Kaczor, J., ... \& Szczodrak, J. (2016). Cultivation and utility of Piptoporus betulinus fruiting bodies as a source of anticancer agents. World Journal of Microbiology and Biotechnology, 32(9), 151. https://doi.org/10.1007/s11274-016-2114-4

Марамохин Э. В., Сиротина М. В., Зонтиков Д. Н. Культивирование мицелия и изучение фитопатогенности некоторых ксилотрофных базидиомицетов в условиях in vitro // Вестник Нижневартовского государственного университета. 2020. № 2. С. 12-18. https://doi.org/10.36906/2311-4444/20-2/02

Maramokhin, E., Sirotina, M., \& Zontikov D. (2020). Cultivation of mycelium and the study of the phytopathogenicity of certain xylotrophic basidiomycetes under in vitro conditions. Bulletin of Nizhnevartovsk State University, (2). 1218. (In Russian). https://doi.org/10.36906/2311-4444/20-2/02 